\title{
Over-the-Counter Drugs and Complementary Medications Use among Children in Southern Italy
}

\author{
Claudia Pileggi, Valentina Mascaro, Aida Bianco, and Maria Pavia \\ Department of Health Sciences, University of Catanzaro "Magna Grcecia”, 88100 Catanzaro, Italy \\ Correspondence should be addressed to Maria Pavia; pavia@unicz.it
}

Received 10 April 2015; Accepted 14 May 2015

Academic Editor: Harold K. Simon

Copyright (C) 2015 Claudia Pileggi et al. This is an open access article distributed under the Creative Commons Attribution License, which permits unrestricted use, distribution, and reproduction in any medium, provided the original work is properly cited.

\begin{abstract}
The use of nonprescription medicines (NPDs) for children illnesses without a doctor's suggestion can lead to unnecessary medication use and is not free of risks. The aim of our study was to examine attitudes and practice of parents towards NPDs use for their children. We also investigated the conditions that may predict NPDs use. A cross-sectional survey was conducted on parents of children attending Community Based Pediatrician (CBP) consultation and data were collected through structured interviews. Positive attitude on NPDs use was reported by $71.4 \%$ of parents, and $61.5 \%$ of them had administered NPDs in the previous 6 months. Antipyretic drugs were the most frequently used medication class without the supervision of the CBP. A positive attitude towards NPDs was significantly more frequent in parents who did not use the CBP as the sole source of information about drugs. The study demonstrated a widespread use of NPDs in children in our context, supported by a substantial positive attitude towards their safety. However, considering potential harms related to some NPDs and the finding that most parents rely on CBP advice, role of CBP on appropriate use of NPDs by parents should be emphasized.
\end{abstract}

\section{Introduction}

Use of nonprescription drugs (NPDs), including over-thecounter drugs (OTCDs) and complementary alternative medicines (CAMs), is widespread all over the world as a first course of action for a range of childhood complaints $[1,2]$. These include mild and moderate conditions, pain [3] and fever [4], and behavioral problems, such as irritability or sleeplessness [5, 6].

OTCDs are defined as safe and effective for use by the general public without a doctor's prescription $[7,8]$, whereas CAMs are a group of diverse medical and health care practices that are not considered part of conventional medicine [9]. CAMs are usually regarded safer than conventional medicines [10]. Parents may give CAMs to their child after having tried conventional medicines without success or in association with conventional medicines [11, 12]. The reason for CAMs use may also be the opportunity to have more options in the health care of children and to increase the likelihood that something would be helpful for the child $[13,14]$.
The use of NPDs is not free of risks, even if adverse effects of CAMs have been found to be minor and self-limiting [15, 16]. Inappropriate treatment of illness and symptoms can lead to unnecessary medication use and possible adverse effects $[15,17]$ if the parents' personal experience is not associated with the right information given by the physician [15].

In Italy, this should be not an issue since primary care is placed at the heart of the health care system. All residents are registered with a primary care physician (PCP) when they reach the age of 15 and, before this age, with a community based pediatrician (CBP). PCP and CBP provide various primary care services, such as health promotion and preventive activities, diagnosis, treatment, and follow-up of acute and chronic conditions. They also act as gate-keepers for access to secondary health services and for drug prescription for all patients in their list. These services are provided, within the National Health Service (NHS), to all patients free of charge, or at a minimal charge. When the PCP and CBP's office is closed Continuity of Care service provides night and weekend coverage as well as urgent home care to all patients. Finally, 
CBP can join a group practice with other CBPs so expanding access times to the study.

Since 2006 in Italy NPDs can be bought not only in pharmacies but also in supermarkets corners. This has raised some concern for the possibility of a more inappropriate use of these medications.

Parental attitudes toward children's medication have been studied quite widely [18], whereas there is a lack of literature investigating OTCDs and CAMs administration by parents in case of illness of their children and most studies have investigated management of specific diseases $[5,19-21]$ or have analyzed the use of a single category of NPDs: OTCDs $[20,21]$ or CAMs [16].

The primary aim was to examine attitudes and practice of parents towards NPDs use for their children. The secondary aim was to investigate the conditions, as sociodemographic characteristic, child health status, and source of information about drugs, which may predict NPDs use by parents.

\section{Materials and Methods}

2.1. Study Population. This cross-sectional study was conducted at waiting rooms of 8 CBPs in Catanzaro (Southern Italy), randomly selected from the list provided by the Local Health Units (LHU) including 37 CBPs that cover the healthcare needs of 56,520 pediatric patients.

From May 2013 through January 2014 all consecutive parents of $\leq 14$ years old children attending CBP consultation and agreeing to participate were interviewed by trained physicians, not involved in patients care.

We investigated the use of both categories of NPDs: OTCDs and CAMs. Categories of drugs included in OTCDs were analgesics, laxative and antidiarrheal, cough and cold preparations, antihistamines, and dermatological, throat, and nasal preparations. As regard to CAMs we included several biologically based therapies as homeopathic and naturopathic medicines (e.g., calendula, royal jelly, and propolis), dietary supplements (including vitamin supplements), and probiotics. We excluded mind-body and manipulative therapies, such as meditation, chiropractic care, and yoga.

2.2. Review Instrument. The questionnaire included 27 questions divided into 4 sections. Each section elicited responses in a variety of formats: closed-ended questions with multiple answers possible, yes or no questions, and open option questions.

The first section explored sociodemographic characteristics of the parent. In the second section we investigated child health status. We used SF-10 for Children that is a 10item instrument meant to be administered to the parents which measures eight domains of health and can be scored to produce physical and psychosocial health status summary scores [22]. This survey tool is intended for children between the ages of 5 and 18 years, and is available with a standard fourweek recall period. Our population was also composed of parents of $<5$ years old children and, for such reason, we have chosen three questions of the SF-10 questionnaire (specifically questions numbers 1, 5, and 9) that could be asked to these parents too and could measure the perception of children's general health status. We also asked about chronic illnesses affecting the child and regularly used prescription drugs.

In the third part we investigated information about the use of OTCDs and CAMs without the CBP's suggestion in relation to child's ailments. Survey participants were first provided the following list of pediatric illnesses and symptoms: fever, upper respiratory infection/cold, sore throat, cough, vomiting, diarrhea, nausea, abdominal pain, dermatological problems (itchiness/redness of the skin, insect bites), allergies, wheezing, sleeping disorders, and headache. For each symptom parents were asked (1) whether their child had that illness or symptom in the previous six months, (2) whether they had administered an NPD, and (3) which NPD they had chosen.

Finally we explored sources of information concerning the child's medication and influences on medication use (e.g., CBP, internet, pharmacist, media, or personal experience). Informed consent was obtained from all responders, and the confidentiality of responses was assured. The questionnaire was pretested on a sample of parents to ensure clarity of interpretation and ease of completion to improve the validity of responses and the included information. Minor modifications on the sequence of questions and format were made on the basis of the pilot study. No medical records or interviews by any pediatrician were used as sources of data.

The study protocol was ratified by the Institutional Ethical Committee ("Mater Domini" Hospital of Catanzaro, Italy) (7 May 2013).

2.3. Statistical Analysis. Data were stored and analyzed using an appropriate database. Statistical analysis was performed using STATA software program, version 11 (Stata Corporation, College Station, Tx). Data were summarized using frequencies and percentages for categorical data and mean and standard deviations for continuous data. In the primary analysis we used the $t$-test (for continuous variables) and Pearson's chi-square (for categorical variables), to examine the association between NPDs use and several explanatory variables.

Multivariate logistic regression model was developed in order to describe the profile of parents who reported positive attitude on NPDs use for their children compared to those with a negative attitude (Model 1). Moreover, multinomial logistic regression analysis was used to investigate, in the subgroup of parents with positive attitude toward NPDs, determinants of the use of NPDs in presence of child's ailments. In particular, we have selected four target symptoms (cold, diarrhea, dermatological problems, and headache) among those reported by parents from the general list (Model 2 ). In this model the outcome variable was categorized into three levels: parents who did not utilize any drug when their child was ill, parents who utilized NPDs without the supervision of the CBP (baseline group), and parents who utilized NPDs only at the suggestion of the CBP.

Results are presented as odds ratio (ORs) and 95\% CIs. All reported $p$ values are two-tailed and a value $<0.05$ was considered statistically significant. 


\section{Results}

The overall response rate was $98.6 \%$ resulting in 728 participating parents. Characteristics of the respondents and their children are fully described in Table 1.

The vast majority of respondents were mothers (89.3\%) and the average age was 36.3 years ( $\mathrm{SD} \pm 6.9$ ). Only $52.9 \%$ were employed. Mean age of children was 4.6 years $(\mathrm{SD} \pm$ 3.4); $15.9 \%$ had a chronic illness diagnosed by a physician and $11.3 \%$ regularly used at least one prescribed medicine; antihistamines (74.4\%) and corticosteroids (11\%) were the most commonly prescribed drugs used, especially for allergic symptoms. More than half of the respondents preferred CBP as the only source of information about drugs.

Positive attitude on NPDs use without the supervision of the CBP was reported by $74.4 \%$ of the respondents, whereas $61.5 \%$ of them had administered NPDs to their children in the last 6 months. In this subgroup, antipyretic drugs were the most frequently used medication class without the supervision of the CBP. Paracetamol was the first choice drug for fever (95\%) or headache (49\%). More than half of the parents chose CAMs (especially herbal products) in presence of cough. Probiotic strains (e.g., lactobacilli spp.) were the most common products for gastrointestinal disorders (61\%). For dermatological symptoms parents chose corticosteroid based drugs (22\%) and CAMs (e.g., calendula, Apis mellifica) (14\%). Vitamin supplements were utilized by $27 \%$ and herbal supplement (e.g. propolis, royal jelly) by $14 \%$ to strengthen children immune system. Results of the univariate analysis suggested that older parents ( $\chi^{2}=20.66,1 \mathrm{df}, p<0.0001$ ), with lower education level $\left(\chi^{2}=5.44,1 \mathrm{df}, p=0.02\right)$ and with higher number of children in the family $\left(\chi^{2}=87.6\right.$, $2 \mathrm{df}, p<0.0001$ ), were significantly more likely to have a positive attitude towards NPDs use. Also, positive attitude was significantly higher in parents of older children $(t$-test $=$ $-5.75,726 \mathrm{df}, p<0.001)$, with chronic diseases $\left(\chi^{2}=13.2\right.$, $1 \mathrm{df}, p<0.001)$, and that regularly used prescribed drugs $\left(\chi^{2}=12.9,1 \mathrm{df}, p<0.001\right)$. Moreover, a positive attitude towards NPDs was significantly more frequent in parents who did not use the CBP as the sole source of information about drug characteristics ( $\chi^{2}$ for trend $=14.3,1 \mathrm{df}, p=$ 0.001 ), selection ( $\chi^{2}$ for trend $=29.11,1 \mathrm{df}, p<0.001$ ), and dose $\left(\chi^{2}\right.$ for trend $\left.=16.72,1 \mathrm{df}, p<0.001\right)$, who gather information about drugs before using them $\left(\chi^{2}=5.63,1 \mathrm{df}\right.$, $p=0.018$ ), and who used dose recommendations provided on the product label ( $\left.\chi^{2}=19.7,1 \mathrm{df}, p<0.001\right)$. Moreover, parents who used NPDs in the last 6 months were more likely to consult sources of information different from CBP $\left(\chi^{2}=48.06,2 \mathrm{df}, p<0.001\right)$. When the multivariate logistic analysis was performed, a positive attitude towards NPDs use was significantly associated with higher number of children in the family ( $\mathrm{OR}=2.04,95 \% \mathrm{CI}=1.50-2.78$ ) and with the presence of limitations in the children activities because of physical health problems (OR $=3.28,95 \% \mathrm{CI}=1.79$ 6.02); furthermore significant associations with information sources about medications were also confirmed $(\mathrm{OR}=3.13$, $95 \% \mathrm{CI}=1.62-6.04 ; \mathrm{OR}=2.9,95 \% \mathrm{CI}=1.75-4.8)($ Table 2$)$.
303 parents were eligible to estimate NPDs use in presence of at least one of the target symptoms. Of them, 27\% reported no drugs use, 58\% NPDs without the supervision of the CBP, and $16 \%$ drugs only suggested by the CBP. Multinomial logistic regression model (Table 3 ) highlighted that choosing $\mathrm{CBP}$ as favorite source of information about drugs characteristics and always gathering information before administering the drug were significantly associated to no drugs use in presence of target symptoms, compared to NPD use without CBP supervision. Also, parents' perception of their children health status significantly influenced behaviors in presence of children illness. Indeed, parents who perceived limitations in children activities because of psychological health problems $(\mathrm{RRR}=4.57,95 \% \mathrm{CI}=1.66-12.58)$ and absence of limitations because of physical health problems $(\mathrm{RRR}=0.26,95 \% \mathrm{CI}=0.11-0.66)$ were more likely to use medications only after suggestion of the CBP.

\section{Discussion}

The results of this study showed that about two-thirds of parents had a positive attitude towards NPDs and have used them in the last six months for their children. $58.3 \%$ of parents used NPDs without CBP supervision in case of children's symptoms (cold, diarrhea, dermatological problems, and headache). Also, a vast majority of our sample showed a belief in self-care that might be favored by the opportunity to buy the drugs in the supermarket corner, where customers can choose medicines by themselves, as well as products like herbal remedies and cosmetics. These findings may appear in contrast with the organization of the Italian NHS in which all the children are assigned to a certain CBP since birth, without any charge, where PCP is the first figure consulted about health needs, because patients are mainly confident in professional skills and satisfied regarding the interpersonal relationship, and drug prescriptions are the most frequent outcome after a PCP consultation [23]. However, it may be hypothesized that the consequence of this favorable condition makes the parents confident in their ability to self-medicate their children. This is confirmed by the results of a recent survey that investigated parental and CBPs' knowledge and management of fever in Italian preschool children, which highlighted that there were not substantial differences regarding both correct and incorrect practices used by parents and by CBPs [24].

The prevalence of positive attitude of NPD in the present study was higher than that found among parents in other countries [10, 18]. However, these studies focused their interest on attitude about OTC medicines only, whereas we examined attitude of NPDs including both OTCDs and CAMs, since the difference between the two categories of medicines may be unclear to some consumers [25]. Moreover, the profile of parents with positive attitude towards NPDs was in accordance with that highlighted in previous studies $[10,18]$.

Our findings on NPDs use are in line with previous results highlighting that paracetamol was the most frequently used OTCD, in particular in children with fever or pain 
TABLE 1: Distribution of the attitude of use of nonprescription drugs (NPDs) according to selected characteristics of the study population.

\begin{tabular}{|c|c|c|c|c|}
\hline & $\begin{array}{c}\text { Total } \\
(N=728)\end{array}$ & $\%$ & $\begin{array}{l}\text { Positive attitude } \\
\text { on NPDs }{ }^{\mathrm{a}} \text { use } \\
(N=505)^{\mathrm{b}}\end{array}$ & $\%$ \\
\hline \multicolumn{5}{|l|}{ Respondent } \\
\hline Mother & 650 & 89.3 & 447 & 68.8 \\
\hline \multirow[t]{2}{*}{ Other relatives (father, grandparents) } & 78 & 10.7 & 58 & 74.4 \\
\hline & & & \multicolumn{2}{|c|}{$\chi^{2}=1.02,1 \mathrm{df}, p=0.312$} \\
\hline \multicolumn{5}{|l|}{ Age (years) } \\
\hline$<35$ & 304 & 41.8 & 183 & 60.2 \\
\hline \multirow[t]{2}{*}{$\geq 35$} & 424 & 58.2 & 322 & 75.9 \\
\hline & & & \multicolumn{2}{|c|}{$\chi^{2}=20.66,1 \mathrm{df}, p<0.001$} \\
\hline \multicolumn{5}{|l|}{ Marital status } \\
\hline Married/cohabitees & 707 & 97.1 & 488 & 69 \\
\hline \multirow[t]{2}{*}{ Other (single, separated/divorced, or widow) } & 21 & 2.9 & 17 & 81 \\
\hline & & & \multicolumn{2}{|c|}{$\chi^{2}=1.37,1 \mathrm{df}, p=0.243$} \\
\hline \multicolumn{5}{|l|}{ Education level (years of schooling) } \\
\hline$<8$ & 142 & 19.5 & 110 & 77.5 \\
\hline \multirow{2}{*}{$\geq 8$} & 586 & 80.5 & 395 & 67.4 \\
\hline & & & \multicolumn{2}{|c|}{$\chi^{2}=5.44,1 \mathrm{df}, p=0.02$} \\
\hline \multicolumn{5}{|l|}{ Working activity } \\
\hline No & 343 & 47.1 & 241 & 70.3 \\
\hline \multirow[t]{2}{*}{ Yes } & 385 & 52.9 & 264 & 69.6 \\
\hline & & & \multicolumn{2}{|c|}{$\chi^{2}=0.24,1 \mathrm{df}, p=0.621$} \\
\hline \multicolumn{5}{|l|}{ Number of children in the family } \\
\hline 1 & 330 & 45.3 & 171 & 51.8 \\
\hline 2 & 312 & 42.9 & 263 & 84.3 \\
\hline \multirow[t]{2}{*}{$\geq 3$} & 86 & 11.8 & 71 & 82.3 \\
\hline & & & \multicolumn{2}{|c|}{$\chi^{2}=87.6,2 \mathrm{df}, p<0.001$} \\
\hline \multicolumn{5}{|l|}{ Child } \\
\hline Gender & & & & \\
\hline Male & 398 & 54.7 & 280 & 70.4 \\
\hline Female & 330 & 45.3 & 225 & 68.2 \\
\hline & & & $\chi^{2}=0.4,1 \mathrm{df}$ & .527 \\
\hline Age (years) & & & & \\
\hline $0-2$ & 219 & 30.1 & 116 & 53 \\
\hline $3-6$ & 341 & 46.8 & 256 & 75.1 \\
\hline $7-11$ & 133 & 18.3 & 107 & 80.5 \\
\hline$>11$ & 35 & 4.8 & 26 & 74.3 \\
\hline Mean \pm SD & 4.6 & & $5 \pm$ & \\
\hline & & & $t=-5.75,726 \mathrm{~d}$ & 0.001 \\
\hline Chronic illness diagnosed by a physician & & & & \\
\hline No & 612 & 84.1 & 408 & 66.7 \\
\hline Yes & 116 & 15.9 & 97 & 83.6 \\
\hline & & & $\chi^{2}=13.2,1 \mathrm{~d}$ & 0.001 \\
\hline Prescribed medicine regularly used & & & & \\
\hline No & 646 & 88.7 & 434 & 67.2 \\
\hline Yes & 82 & 11.3 & 71 & 86.6 \\
\hline & & & $\chi^{2}=12.9,1 \mathrm{df}$ & .001 \\
\hline General health perception by the parents & & & & \\
\hline Poor/fair & 57 & 7.6 & 44 & 80.0 \\
\hline Good/very good/excellent & 673 & 92.5 & 461 & 68.5 \\
\hline & & & $\chi^{2}=3.16,1 \mathrm{df}$ & 0.075 \\
\hline Source of information about medications (727; 99. & & & & \\
\hline Favorite source of information about medication & & & & \\
\hline Only pediatrician & 397 & 54.6 & 255 & 64.2 \\
\hline Pediatrician and other source ${ }^{c}$ & 294 & 40.4 & 218 & 74.2 \\
\hline Other source $^{c}$ & 36 & 5 & 32 & 88.9 \\
\hline
\end{tabular}


TABLe 1: Continued.

\begin{tabular}{|c|c|c|c|c|}
\hline & $\begin{array}{c}\text { Total } \\
(N=728)\end{array}$ & $\%$ & $\begin{array}{l}\text { Positive attitude } \\
\text { on NPDs }{ }^{\mathrm{a}} \text { use } \\
(N=505)^{\mathrm{b}}\end{array}$ & $\%$ \\
\hline & & & $\chi^{2}$ for trend $=14$ & $p=0.001$ \\
\hline \multicolumn{5}{|l|}{ Influences on medications selection } \\
\hline Only pediatrician & 412 & 56.7 & 259 & 62.9 \\
\hline Pediatrician and other influences ${ }^{\mathrm{d}}$ & 196 & 27 & 140 & 71.4 \\
\hline \multirow[t]{2}{*}{ Other influences ${ }^{\mathrm{d}}$} & 119 & 16.4 & 106 & 89.1 \\
\hline & & & $\chi^{2}$ for trend $=29.1$ & $p<0.001$ \\
\hline \multicolumn{5}{|c|}{ Use of product label or other kind of information before administering the drug } \\
\hline No & 172 & 23.7 & 132 & 76.7 \\
\hline \multirow[t]{2}{*}{ Yes } & 555 & 76.3 & 373 & 67.2 \\
\hline & & & $\chi^{2}=5.63,1 \mathrm{~d}$ & 0.018 \\
\hline \multicolumn{5}{|c|}{ Use of dosing recommendations provided on the product label } \\
\hline No & 575 & 79.1 & 377 & 65.6 \\
\hline \multirow[t]{2}{*}{ Yes } & 152 & 20.9 & 128 & 84.2 \\
\hline & & & \multicolumn{2}{|c|}{$\chi^{2}=19.7,1 \mathrm{df}, p<0.001$} \\
\hline \multicolumn{5}{|l|}{ Favorite source for dose information ${ }^{\mathrm{e}}$} \\
\hline Only pediatrician & 492 & 85.6 & 307 & 62.4 \\
\hline Pediatrician and other source ${ }^{c}$ & 61 & 10.6 & 49 & 80.3 \\
\hline \multirow[t]{2}{*}{ Other source ${ }^{c}$} & 22 & 3.8 & 21 & 95.5 \\
\hline & & & \multicolumn{2}{|c|}{$\chi^{2}$ for trend $=16.72,1 \mathrm{df}, p<0.001$} \\
\hline
\end{tabular}

${ }^{\mathrm{a}}$ Nonprescription drugs.

${ }^{\mathrm{b}}$ In brackets, the number and the percentage of the total sample of 728 subjects responding to the question.

${ }^{\mathrm{c}}$ Internet, books, nurse, friends/family, pharmacist, media (newspaper/TV/magazines/radio), child care/teacher, or personal experience.

${ }^{\mathrm{d}}$ Cost, packaging, advertising by media, pharmacist/physician/nurse endorsement, friend/family endorsement, child care worker, or personal choice.

${ }^{\mathrm{e}} 575$ subjects were eligible, because they did not always use product label for dose information.

TABLE 2: Result of the logistic regression model for estimates of associations of attitude on nonprescription drugs (NPDs) with potential determinants of their use.

Attitude on NPDs ${ }^{\text {a }}$ use

Log likelihood $=-360.57, \chi^{2}=125.28,10 \mathrm{df}, p<0.001$, and number of participants $=705$

\begin{tabular}{|c|c|c|c|c|}
\hline Variable & OR & SE & $95 \% \mathrm{CI}$ & $p$ \\
\hline \multicolumn{5}{|l|}{ Sociodemographic profile } \\
\hline Number of children in the family, continuous & 2.04 & 0.32 & $1.50-2.78$ & $<0.001$ \\
\hline Age of respondent ( $<35$ years old as reference) & 1.20 & 0.23 & $0.82-1.75$ & 0.35 \\
\hline Marital status (other ${ }^{\mathrm{b}}$ as reference) & 0.58 & 0.35 & $0.18-1.88$ & 0.36 \\
\hline Education level ( $<8$ years of schooling as reference) & 0.81 & 0.21 & $0.49-1.33$ & 0.40 \\
\hline \multicolumn{5}{|l|}{ Children's health status } \\
\hline $\begin{array}{l}\text { Limitations in schoolwork or activities with friends because of physical } \\
\text { health problems (absence of limitations as reference) }\end{array}$ & 3.28 & 1.01 & $1.79-6.02$ & $<0.001$ \\
\hline Prescribed medicine regularly used by the child (none as reference) & 1.81 & 0.67 & $0.87-3.74$ & 0.11 \\
\hline General health perception by the parents (poor/fair as reference) & 0.69 & 0.28 & $0.30-1.55$ & 0.36 \\
\hline \multicolumn{5}{|l|}{ Source of information about medications } \\
\hline \multicolumn{5}{|l|}{ Influences on medications selection (only pediatrician as reference) } \\
\hline Pediatrician and other source ${ }^{c}$ & \multicolumn{4}{|c|}{ Backward elimination } \\
\hline Only other source ${ }^{c}$ & 3.13 & 1.05 & $1.62-6.04$ & 0.001 \\
\hline $\begin{array}{l}\text { Utilization of product label or other information before administering the } \\
\text { drug (no as reference) }\end{array}$ & 0.73 & 0.17 & $0.47-1.16$ & 0.18 \\
\hline $\begin{array}{l}\text { Utilization of dosing recommendations provided on the product label } \\
\text { (never/hardly ever/sometimes/often as reference) }\end{array}$ & 2.90 & 0.75 & $1.75-4.80$ & $<0.001$ \\
\hline
\end{tabular}

${ }^{a}$ Nonprescription drugs.

${ }^{\mathrm{b}}$ Single, separated/divorced, or widow.

${ }^{c}$ Internet, books, nurse, friends/family, pharmacist, media (newspaper/TV/magazines/radio), child care/teacher, or personal experience. 
TABLE 3: Result of the multinomial logistic regression model for estimates of nonprescription drugs (NPDs) use in the presence of at least one of 4 symptoms (cold, diarrhea, dermatological problems, and headache).

\begin{tabular}{|c|c|c|c|c|}
\hline \multicolumn{5}{|c|}{$\begin{array}{l}\text { Outcome: } \mathrm{NPDs}^{\mathrm{a}} \text { utilization without supervision of the CBP } \\
\text { Log likelihood }=-264.20, \chi^{\mathrm{b}}=52.63,34 \mathrm{df}, p=0.02 \text {, and number of participants }=303\end{array}$} \\
\hline \multirow{2}{*}{ Variable } & \multicolumn{2}{|c|}{ No medications users } & \multicolumn{2}{|c|}{ Medications users at the suggestion of the $\mathrm{CBP}^{\mathrm{b}}$} \\
\hline & RRR (95\% CI) & $p$ value & RRR (95\% CI) & $p$ value \\
\hline \multicolumn{5}{|l|}{ Sociodemographic profile } \\
\hline Respondent (other ${ }^{\mathrm{c}}$ as reference) & $1.20(0.37-3.86)$ & 0.76 & $0.74(0.17-3.19)$ & 0.68 \\
\hline Age of respondent, continuous & $0.96(0.91-1.02)$ & 0.18 & $1.00(0.94-1.07)$ & 0.89 \\
\hline Marital status (other ${ }^{\mathrm{d}}$ as reference) & $6.38(0.71-57.4)$ & 0.10 & $3.61(0.39-33.31)$ & 0.26 \\
\hline Education level ( $<8$ years of schooling as reference) & $0.77(0.36-1.62)$ & 0.49 & $0.92(0.35-2.41)$ & 0.86 \\
\hline Working activity (none as reference) & $0.88(0.48-1.63)$ & 0.69 & $1.18(0.56-2.49)$ & 0.67 \\
\hline Number of children in the family, continuous & $1.20(0.78-1.84)$ & 0.33 & $1.25(0.75-2.11)$ & 0.39 \\
\hline Child gender (male as reference) & $1.09(0.61-1.95)$ & 0.76 & $0.64(0.31-1.31)$ & 0.22 \\
\hline Age of the child, continuous & $0.98(0.89-1.08)$ & 0.66 & $0.95(0.84-1.07)$ & 0.38 \\
\hline \multicolumn{5}{|l|}{ Children's health status } \\
\hline \multicolumn{5}{|l|}{$\begin{array}{l}\text { Parental general health perception (poor/fair as } \\
\text { reference) }\end{array}$} \\
\hline Good/very good/excellent & $2.67(0.81-8.82)$ & 0.11 & $1.89(0.43-8.26)$ & 0.40 \\
\hline $\begin{array}{l}\text { Limitations in schoolwork or activities with friends } \\
\text { because of physical health problems (absence of } \\
\text { reference) }\end{array}$ & $0.56(0.27-1.15)$ & 0.11 & $0.26(0.11-0.66)$ & 0.004 \\
\hline $\begin{array}{l}\text { Limitations in schoolwork or activities with friends } \\
\text { because of psychological health problems (absence as } \\
\text { reference) }\end{array}$ & $1.76(0.65-4.78)$ & 0.27 & $4.57(1.66-12.58)$ & 0.003 \\
\hline $\begin{array}{l}\text { Child's chronic illness diagnosed by a physician } \\
\text { (absence as reference) }\end{array}$ & $0.78(0.21-2.87)$ & 0.71 & $0.52(0.09-3.12)$ & 0.48 \\
\hline $\begin{array}{l}\text { Prescribed medicine regularly used by the child (none } \\
\text { as reference) }\end{array}$ & $1.37(0.32-5.82)$ & 0.67 & $3.06(0.48-19.46)$ & 0.24 \\
\hline \multicolumn{5}{|l|}{ Source of information about medications } \\
\hline \multicolumn{5}{|l|}{$\begin{array}{l}\text { Favorite source of information about medications } \\
\text { characteristics (only pediatrician as reference) }\end{array}$} \\
\hline Pediatrician and other source & $0.46(0.25-0.84)$ & 0.01 & $1.05(0.51-2.19)$ & 0.89 \\
\hline Only other source $e^{e}$ & $0.25(0.06-0.96)$ & 0.04 & $0.63(0.15-2.61)$ & 0.52 \\
\hline \multicolumn{5}{|l|}{$\begin{array}{l}\text { Utilization of product label or other information before } \\
\text { administering the drug (never/hardly } \\
\text { ever/sometimes/often as reference) }\end{array}$} \\
\hline Always & $2.23(1.08-4.63)$ & 0.03 & $1.24(0.54-2.84)$ & 0.61 \\
\hline $\begin{array}{l}\text { Utilization of dosing recommendations provided on the } \\
\text { product label (no as reference) }\end{array}$ & $0.63(0.29-1.35)$ & 0.24 & $1.20(0.51-2.81)$ & 0.68 \\
\hline
\end{tabular}

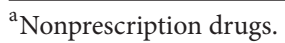

${ }^{\mathrm{b}}$ Community based pediatrician.

${ }^{c}$ Father or grandparents.

${ }^{\mathrm{d}}$ Single, separated/divorced, or widow.

${ }^{\mathrm{e}}$ Cost, packaging, advertising by media, pharmacist endorsement, physician endorsement, nurse endorsement, friend/family endorsement, child care worker, or personal choice.

$[19,26,27]$. Even if paracetamol seems to be the drug of choice in the management of illnesses and injuries at home, it is also acknowledged to be the medication most frequently implicated in intentional and unintentional overdosing and liver toxicity $[17,28]$. The process of safely administering medications is influenced by multiple factors, such as demographic characteristics of the parent $[4,21]$, number of other children [26], and parental perceived child health status [3].
Although it was not within the scope of this study to collect data relating to side effects of the drugs administered at home, the profile of the NPDs users in our survey is quite similar to that of previous studies and, therefore, it is reasonable to assume that the frequency of adverse events is comparable to that reported in the literature [17].

In our study use of CAMs was in agreement with a large survey conducted in the pediatric population in the United 
States [29], as regards to cough (53.9\%) and dermatological manifestations (16.5\%), whereas we found higher CAMs use among children with abdominal pain (25\%).

Previous researchers have found that parents mostly rely on CBP as their main resource for medication information on how to manage children disease at home $[15,26]$, followed by package labels, pharmacists, and nurses [15, 19, 30]. However, as showed by multivariable analysis, parents with a positive attitude to NPDs use prefer other information sources than the CBP, such as internet or media, and so forth. The use of the Internet as a healthcare information resource has been described in the literature, showing that it is mostly used for information on general health, acute or minor illness, chronic conditions, and NPDs [31], although Eiland et al. found that parents do not greatly rely on it for information regarding their children health care [15]. The use of the Internet in this area is still controversial; it offers enormous opportunities, particularly for providing and improving consumer information with regard to health care. The major issue is that it represents an international and unregulated source of information, so parents should be able to interpret the medical ones. It is important to continue research on the use of the Internet among patients and their families. Moreover, institutions and physicians should better utilize web applications to improve patients education [32] and provide tools for them to distinguish the high-quality information. On the other hand, the availability of NPDs in nonpharmacy sources should stimulate CBPs to provide parents with in-depth information about drugs administration to their children and to ensure that parents have understood how to appropriately use OTCDs.

In our study, use of medications only after suggestion of the CBP was more frequent by parents having a worse perception of their children physical health. On the contrary, previous studies $[33,34]$ found that mothers thinking their children were susceptible to illness were more likely to regularly use NPDs.

Almost all of the questionnaires were filled in by mothers, which still represent the main educators in the family and the ones who take care of the family's health care [18]. Therefore, since it has been reported that women are more likely than men to seek self-treatment [35] and that subjects that use self-medication for themselves seem to be positively oriented also towards using it for their children $[10,36]$, women may represent the target population for educative programs on safe self-medication practices.

The results of our study should be interpreted in the light of few potential limitations. First, our survey was performed as cross-sectional and it is well known that cross-sectional design does not allow any cause-effect relationship and poses many problems in relation to hypothesis testing since data on "risk factors" and "outcomes" are assessed at the same time. Second, data were based entirely on patients selfreporting; however, we do not think that method of data collection may represent a problem because self-reporting is the only way to collect subjective information about various domains of perceived health status. Third, as is the case of all questionnaire surveys, another limitation is the potential recall bias. However, recall bias was mitigated by having restricted recall within a specified period.

We did not collect data relating to parents' medications use to identify whether it influenced self-medication for their children. However, as previously stated, the available studies $[10,36]$ showed positive attitudes to self-medication for their children in subjects practising self-medication for themselves. Moreover, we recruited parents through CBPs offices; perhaps parents who use NPDs for their children attend physician's offices less often. However, CBPs in Italy act as "gate keepers" for all children health demands in the NHS and therefore their consultation is widespread within the parents in Italy [30]. Finally, as in previous studies [3, 15], socioeconomic status was not analyzed in our survey, but there were only 15 parents $(2.1 \%)$ that said medicines cost influenced their choice of products, which could mean that health problems are considered individual experiences more important than external factors and economic status. Anyway, recommending an appropriate medication that the parents can afford is imperative.

\section{Conclusion}

The study demonstrated a widespread use of NPDs in children in our context, supported by a substantial positive attitude towards their safety. However, considering potential harms related to some NPDs and the finding that most parents rely on CBP advice, role of CBP on appropriate use of NPDs by parents should be emphasized.

\section{Conflict of Interests}

The authors declare that they have no conflict of interests.

\section{Authors' Contribution}

Professor Claudia Pileggi participated in the conception and design of the study, collected the data, contributed to the data analysis and interpretation, and wrote the first draft of the paper. Drs. Valentina Mascaro and Aida Bianco collected the data and contributed to the data analysis and interpretation. Professor Maria Pavia designed the study, was responsible for the data analysis and interpretation, and wrote the paper. All authors approved the final paper as submitted and agree to be accountable for all aspects of the work.

\section{References}

[1] C. Bond and P. Hannaford, "Issues related to monitoring the safety of Over-The-Counter (OTC) medicines," Drug Safety, vol. 26, no. 15, pp. 1065-1074, 2003.

[2] P. M. Barnes, B. Bloom, and R. L. Nahin, "Complementary and alternative medicine use among adults and children: United States, 2007," National Health Statistics Reports, vol. 10, no. 12, pp. 1-23, 2008.

[3] Y. Du, U. Ellert, W. Zhuang, and H. Knopf, "Analgesic use in a national community sample of German children and adolescents," European Journal of Pain, vol. 16, no. 6, pp. 934943, 2012. 
[4] A. Walsh, H. Edwards, and J. Fraser, "Over-the-counter medication use for childhood fever: a cross-sectional study of Australian parents," Journal of Paediatrics and Child Health, vol. 43, no. 9, pp. 601-606, 2007.

[5] P. Lagerløv, S. Helseth, and T. Holager, "Childhood illnesses and the use of paracetamol (acetaminophen): a qualitative study of parents' management of common childhood illnesses," Family Practice, vol. 20, no. 6, pp. 717-723, 2003.

[6] P. Allotey, D. D. Reidpath, and D. Elisha, "Social medication and the control of children: a qualitative study of over-the-counter medication among australian children," Pediatrics, vol. 114, no. 3, pp. e378-e383, 2004.

[7] Agenzia Italiana del Farmaco, "La ricetta medica," http://www .agenziafarmaco.gov.it/it/content/la-ricetta-medica.

[8] U.S. Food and Drug Administration, "What are Over-thecounter (OTC) drugs and how are they approved?" 2012, http:// www.fda.gov/Drugs/InformationOnDrugs/ucm079436.htm.

[9] National Center for Complementary and Alternative Medicine and National Institutes of Health, "Complementary, alternative, or integrative health: what's in a name?” 2014, http://nccam.nih .gov/health/whatiscam.

[10] S. Siponen, R. Ahonen, V. Kiviniemi, and K. Hämeen-Anttila, "Association between parental attitudes and self-medication of their children," International Journal of Clinical Pharmacy, vol. 35, no. 1, pp. 113-120, 2013.

[11] D. Wood and F. Finlay, "Complementary and alternative medicine use in children with life-limiting conditions," Nursing Children and Young People, vol. 23, no. 4, pp. 31-34, 2011.

[12] A. Huillet, C. Erdie-Lalena, D. Norvell, and B. E. Davis, "Complementary and alternative medicine used by children in military pediatric clinics," The Journal of Alternative and Complementary Medicine, vol. 17, no. 6, pp. 531-537, 2011.

[13] T. J. Zuzak, I. Zuzak-Siegrist, A. P. Simões-Wüst, L. Rist, and G. Staubli, "Use of complementary and alternative medicine by patients presenting to a paediatric Emergency Department," European Journal of Pediatrics, vol. 168, no. 4, pp. 431-437, 2009.

[14] M. O'Keefe and S. Coat, "Increasing health-care options: the perspectives of parents who use complementary and alternative medicines," Journal of Paediatrics and Child Health, vol. 46, no. 6, pp. 296-300, 2010.

[15] L. S. Eiland, M. L. Salazar, and T. M. English, "Caregivers' perspectives when evaluating nonprescription medication utilization in children," Clinical Pediatrics, vol. 47, no. 6, pp. 578$587,2008$.

[16] S. Gottschling, B. Gronwald, S. Schmitt et al., "Use of complementary and alternative medicine in healthy children and children with chronic medical conditions in Germany," Complementary Therapies in Medicine, vol. 21, no. 1, supplement, pp. S61-S69, 2013.

[17] Z. Bárzaga Arencibia and I. Choonara, "Balancing the risks and benefits of the use of over-the-counter pain medications in children," Drug Safety, vol. 35, no. 12, pp. 1119-1125, 2012.

[18] K. Hämeen-Anttila, P. Halonen, S. Siponen, M. Holappa, and R. Ahonen, "Parental attitudes toward medicine use in children in Finland," International Journal of Clinical Pharmacy, vol. 33, no. 5, pp. 849-858, 2011.

[19] E. Purssell, "Treatment of fever and over-the-counter medicines," Archives of Disease in Childhood, vol. 92, no. 10, pp. 900901, 2007.

[20] R. K. Ertmann, J. J. Møller, F. B. Waldorff, V. Siersma, S. Reventlow, and M. Söderström, "The majority of sick children receive paracetamol during the winter," Danish Medical Journal, vol. 59, no. 12, Article ID A4555, 2012.

[21] M. Trajanovska, E. Manias, N. Cranswick, and L. Johnston, "Parental management of childhood complaints: over-thecounter medicine use and advice-seeking behaviours," Journal of Clinical Nursing, vol. 19, no. 13-14, pp. 2065-2075, 2010.

[22] D. M. Turner-Bowker, M. S. Bayliss, M. Kosinski et al., SF-10 for Children: A User's Guide, QualityMetric, Lincoln, RI, USA, 2003.

[23] C. Pileggi, V. Carbone, M. Pavia, and I. F. Angelillo, "Patients' perceptions and related behaviours on role of primary care physician in Italy," European Journal of Public Health, vol. 14, no. 3, pp. 258-260, 2004.

[24] E. Chiappini, A. Parretti, P. Becherucci et al., "Parental and medical knowledge and management of fever in Italian preschool children," BMC Pediatrics, vol. 12, article 97, 2012.

[25] A. Furnham, "Exploring attitudes toward, and knowledge of, homeopathy and CAM through focus groups," Complementary Therapies in Nursing and Midwifery, vol. 8, no. 1, pp. 42-47, 2002.

[26] C. Anderson, P. Rolfe, and A. Brennan-Hunter, "Administration of Over-the-counter medication to children at home-a survey of parents from community health centers," Journal of Community Health Nursing, vol. 30, no. 3, pp. 143-154, 2013.

[27] P. Nydert, E. Kimland, I. Kull, and S. Lindemalm, "Over-thecounter drug use-estimations within the Swedish paediatric population," European Journal of Pediatrics, vol. 170, no. 5, pp. 583-588, 2011.

[28] J. S. Cohen, “The little-known dangers of acetaminophen," Life Extension, vol. 13, pp. 42-49, 2007.

[29] G. S. Birdee, R. S. Phillips, R. B. Davis, and P. Gardiner, "Factors associated with pediatric use of complementary and alternative medicine," Pediatrics, vol. 125, no. 2, pp. 249-256, 2010.

[30] C. Lemer, D. W. Bates, C. Yoon, C. Keohane, G. Fitzmaurice, and R. Kaushal, "The role of advice in medication administration errors in the pediatric ambulatory setting," Journal of Patient Safety, vol. 5, no. 3, pp. 168-175, 2009.

[31] A. Bianco, R. Zucco, C. G. A. Nobile, C. Pileggi, and M. Pavia, "Parents seeking health-related information on the internet: cross-sectional study," Journal of Medical Internet Research, vol. 15, no. 9, article e204, 2013.

[32] S. A. Adams, "Revisiting the online health information reliability debate in the wake of 'web 2.0': an inter-disciplinary literature and website review," International Journal of Medical Informatics, vol. 79, no. 6, pp. 391-400, 2010.

[33] N. Birchley and S. Conroy, "Over-the-counter medicines in childhood: issues and concerns. A narrative review of the literature," Paediatric and Perinatal Drug Therapy, vol. 4, no. 4, pp. 161-167, 2001.

[34] P. Carrasco-Garrido, R. Jiménez-García, V. H. Barrera, A. L. de Andrés, and Á. G. de Miguel, "Medication consumption in the Spanish paediatric population: related factors and time trend, 1993-2003," British Journal of Clinical Pharmacology, vol. 68, no. 3, pp. 455-461, 2009.

[35] L. Garofalo, G. Di Giuseppe, and I. F. Angelillo, "Selfmedication practices among parents in Italy," BioMed Research International, vol. 2015, Article ID 580650, 8 pages, 2015.

[36] M. Moenkhoff, O. Baenziger, J. Fischer, and S. Fanconi, "Parental attitude towards alternative medicine in the paediatric intensive care unit," European Journal of Pediatrics, vol. 158, no. 1, pp. 12-17, 1999. 


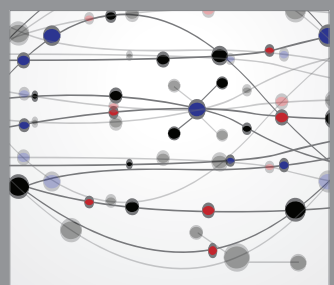

The Scientific World Journal
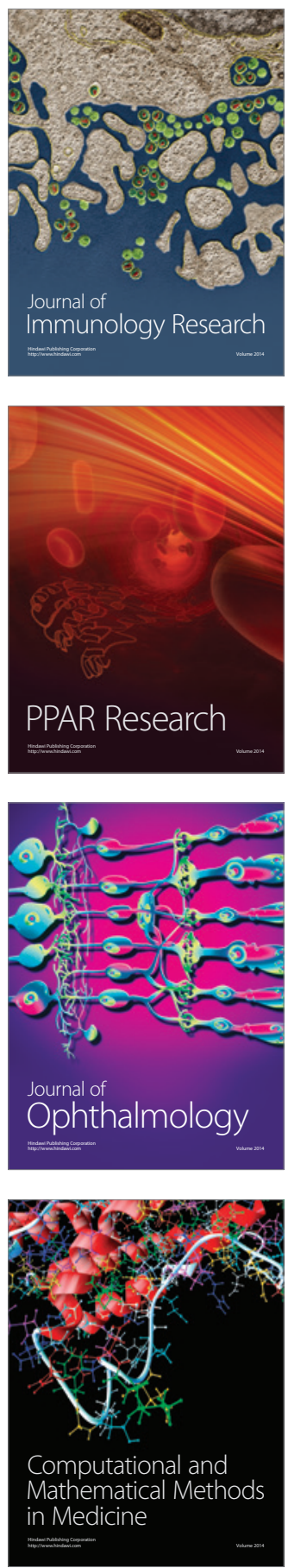

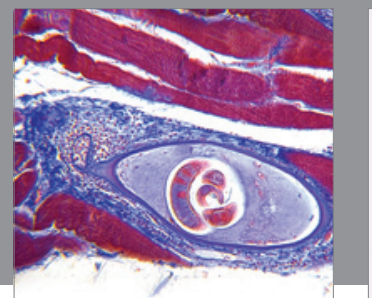

Gastroenterology

Research and Practice
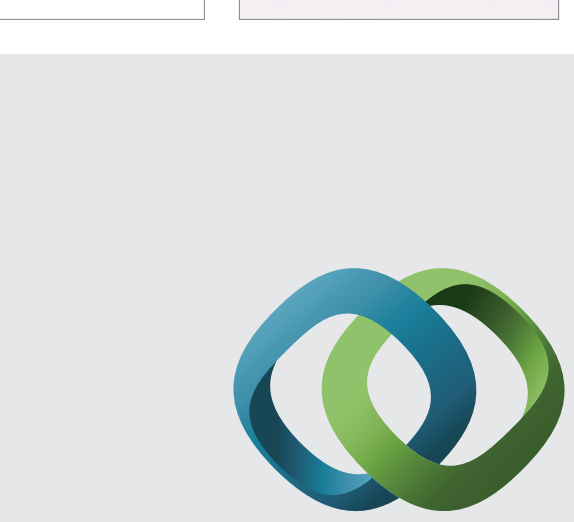

\section{Hindawi}

Submit your manuscripts at

http://www.hindawi.com
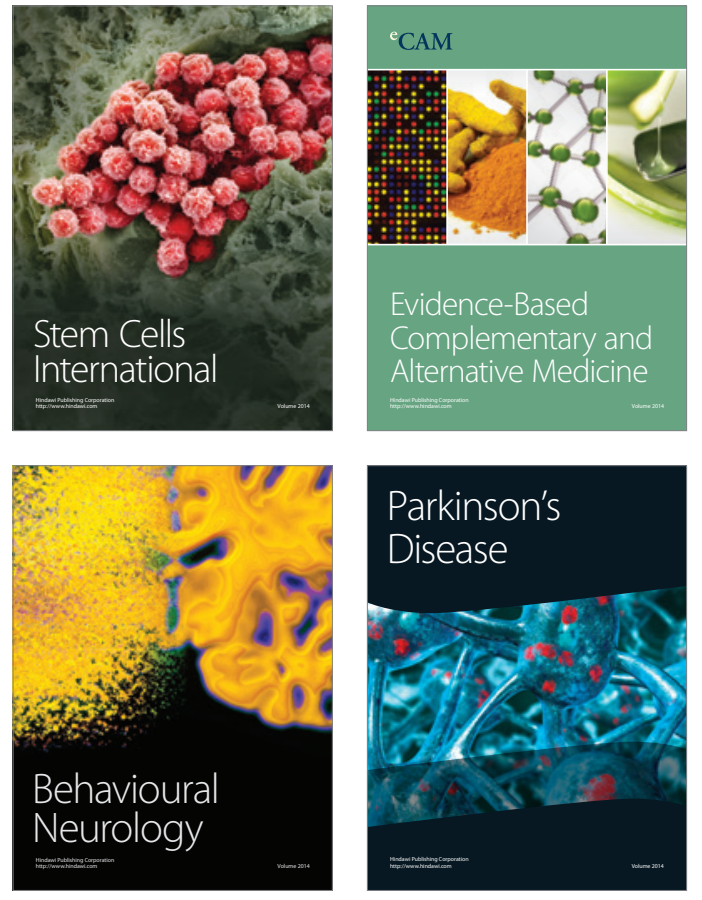
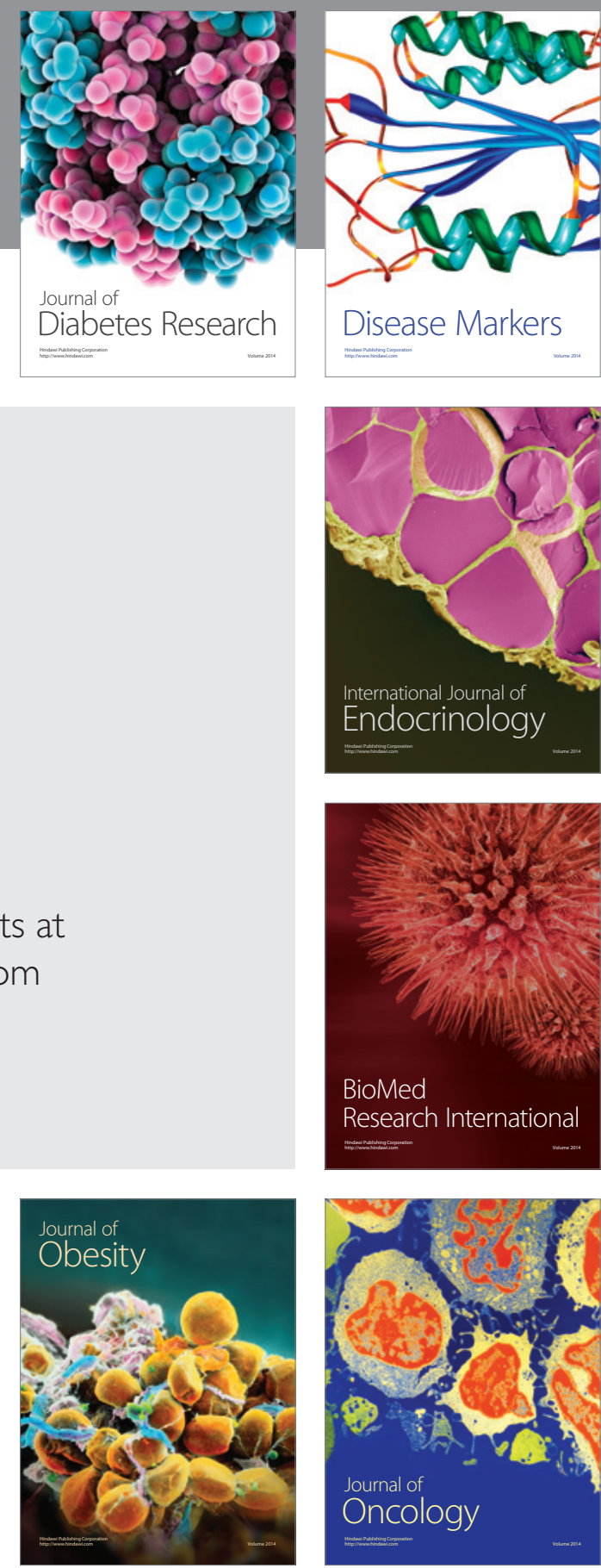

Disease Markers
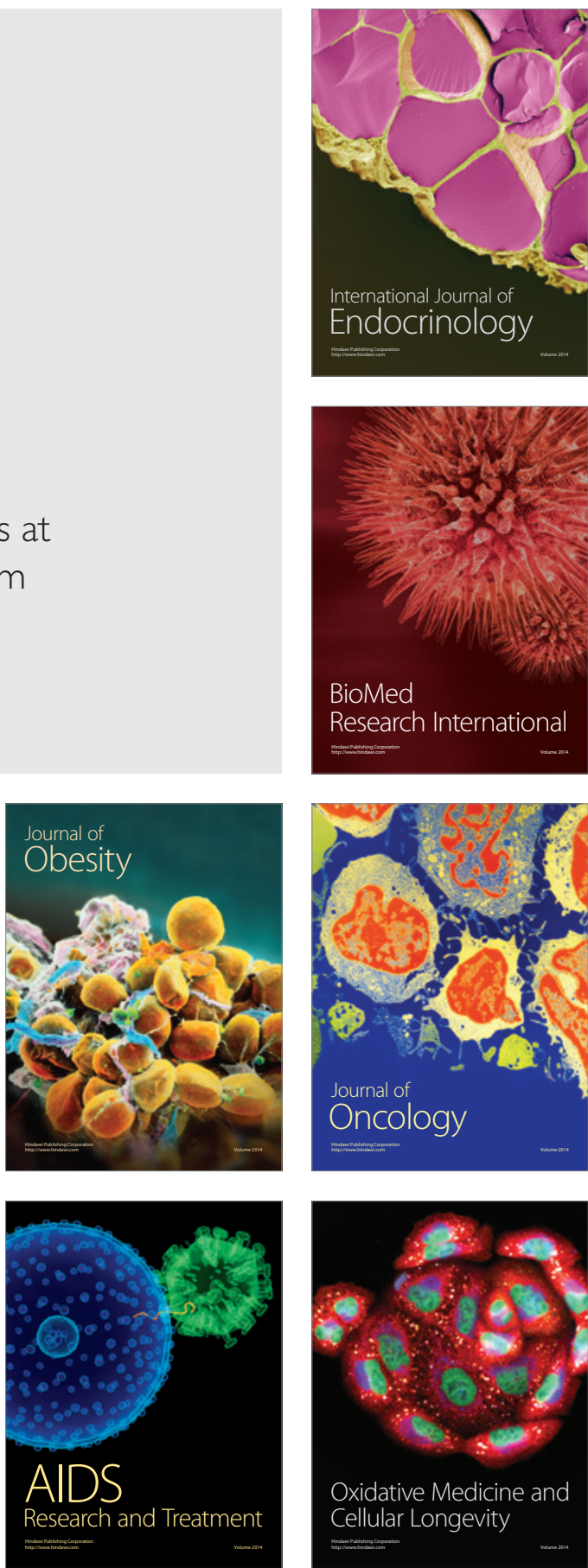